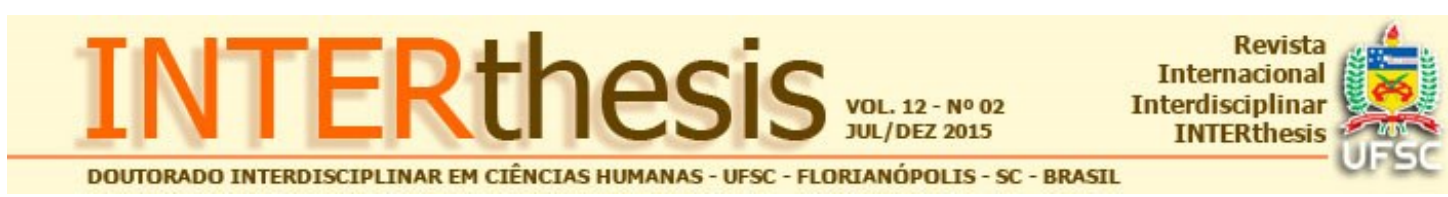

\title{
UMA VISÃO CRÍTICO DISCURSIVA DO RELATO DE DESCENDENTES DE IMIGRANTES ALEMÃES EM TEÓFILO OTONI/MG: CONSTRUINDO NOVAS TERRITORIALIDADES
}

\section{Resumo:}

\author{
Cibele Maria Diniz Figueiredo Gazzinelli ${ }^{1}$ \\ Nádia Dolores Fernandes Biavati²
}

Este artigo tem como objetivo analisar, a partir da visão discursivo-crítica um relato de descendente de imigrantes alemães em Teófilo Otoni, trazendo como destaque teórico metodológico o enquadre de Chouliaraki e Fairclough (1999), bem como as reflexões de Fairclough $(2003 ; 2009)$ cujas conjecturas privilegiam o modo como o discurso se insere na vida social. Analisar o relato a partir desse enquadre teóricometodológico demanda a remissão a todo contexto sócio histórico na medida em que a linguagem enquanto prática social implica um momento social no qual outros se representam e representam suas ações trazendo (re) significações. Assim, apresenta-se a imigração alemã no Brasil, no Vale do Mucuri e de modo especial em Teófilo Otoni- MG. Em seguida, uma discussão acerca das relações sociais que envolvem a desterritorialização de imigrantes e a construção de novas territorialidades. Por fim, apresenta-se a análise de discurso crítica, seguindo para tanto os significados propostos por Fairclough (2003). No significado acional, focalizou-se o gênero relato e a categoria intertextualidade, quando se identificou as vozes articuladas no discurso; no significado representacional, a categoria interdiscursividade, quando se pôde perceber os discursos de cooperação e/ou competição. No significado identificacional, destacou-se a modalidade, bem como a avaliação, quando se pôde perceber as representações de identidades legitimadoras e de resistência. Além disso, identificaram-se traços que conferem à língua, ao trabalho e sobretudo, à religião, valores mantidos pelos descendentes de imigrantes de alemães.

Palavras-chave: Linguagem. Discurso. Imigração. Desterritorialização. Territorialidade.

\section{INTRODUÇÃO}

O presente artigo tem como objetivo apresentar uma discussão teórica que focaliza a Análise de Discurso Crítica como instrumento teórico metodológico para o estudo de relatos de descendente de imigrantes alemães em Teófilo Otoni,

\footnotetext{
${ }^{1}$ Mestre em Gestão Integrada de Território pela Universidade Vale do Rio Doce. Professora de Língua Portuguesa e Produção de textos acadêmicos. Coordenadora do Núcleo de Investigação Científica do Instituto de Ensino Superior Integrado, Teófilo Otoni, MG, Brasil. E-mail: cibeledfg@yahoo.com.br ${ }^{2}$ Doutora em Linguística pela Universidade Federal de Minas Gerais. Professora da Universidade Federal de São João del Rei no programa de Mestrado em Letras, São João del Rei, MG, Brasil. Email: nadiabiavati@yahoo.com.br
}

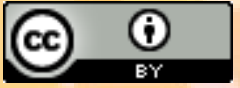
Esta obra foi licenciada com uma Licença Creative Commons - Atribuição 3.0 Não Adaptada. 
(Fairclough,2001;2003;2006;2012), buscando assim não apenas as características linguísticas presentes em relato de um descendente em estudo de caso, mas também as relações sociais e econômicas envolvidas nesse processo. Nessa direção, considera-se o discurso como uma prática social, construção linguística repleta de significações, interpeladas por ideologias, valores e práticas.

Tomando como referência o modelo analítico de Chouliaraki \& Fairclough (1999) e Fairclough (2001), a análise parte de uma questão social e das implicações que contribuem para o estabelecimento dessa questão. A discussão que ora se apresenta é parte da temática discutida em dissertação ${ }^{3}$, considerando os dizeres e o modo como discursivamente apresenta-se e representa-se a imigração alemã para o Brasil. Neste artigo, a análise é feita a partir dos dizeres de uma descendente, personagem significativo que discute, de modo específico, as condições de migração para Teófilo Otoni- MG, de outro modo, como esse processo era compreendido, representado, vivido pelos seus ancestrais diretos, como avós e pais.

Vale destacar o processo do dizer como uma circunstância que redesenha a trajetória dos sujeitos, trazendo à tona esse processo de representar como eles se adaptam às situações diversas e adversas no território de destino, num dado momento sócio histórico. Nesse sentido, chamam atenção os sentidos construídos a partir de todo o contexto social e político desse processo, desde a chegada dos imigrantes em Teófilo Otoni até as implicações sociais, econômicos e políticos desse processo, ou seja, a contextualização desse meio social representa as conjecturas (Chouliaraki \& Fairclough,1999), ou, as práticas nas quais o problema está inserido.

Dessa forma, na primeira seção, busca-se contextualizar a imigração alemã no Brasil, destacando aspectos característicos da política imigratória brasileira, bem como as peculiaridades das colônias alemãs no país. Em seguida, apresentam-se aspectos históricos da imigração alemã no Vale do Mucuri, e de modo específico, no território de Teófilo Otoni, quando se inicia uma discussão prévia entre os aspectos históricos apresentados nos livros de historiadores regionais e alguns sentidos construídos por meio dos relatos da descendente dos imigrantes alemães no local. $\mathrm{Na}$ segunda parte, discute-se a desterritorialização do imigrante alemão por um olhar cultural e a construção de novas territorialidades, tendo em vista a concepção

${ }^{3}$ Discursos sobre imigração: Relatos de descendentes alemães no território de Teófilo Otoni-MG.

R. Inter. Interdisc. INTERthesis, Florianópolis, v.12, n.2, p.74-94, Jul-Dez. 2015 
de território enquanto produto das relações sociais. Em seguida, apresenta-se a justificativa pela abordagem da Análise de Discurso Crítica como um instrumental teórico metodológico e o enquadre adotado para a construção do presente estudo. Por fim, procede-se a análise de um relato em estudo de caso, quando se percebe aspectos que sugerem alguns traços identitários teuto-brasileiro delineados no discurso de uma descendente, como um recorte possível para o estudo sobre a descendência alemã em Teófilo Otoni.

\section{METODOLOGIA:}

O estudo apresentou abordagem qualitativa, uma vez que se trabalhou com o universo de significados, crenças e valores, representados discursivamente no relato oral de dez entrevistados, todos descendentes de imigrantes alemães, sendo observado o significado trazido por essas pessoas por meio das suas escolhas discursivas. Como já exposto, neste artigo apresenta-se um recorte: a análise de um relato de uma descendente de imigrantes alemães da dissertação "Discursos sobre imigração: Relatos de descendentes alemães no território de Teófilo Otoni-MG". Esse primeiro relato foi feito na primeira etapa do trabalho, quando foi realizada uma pesquisa exploratória na qual foi identificada uma descendente que parecia ser 'representante-arquivo'4. Tal denominação se deve ao fato de essa pessoa ser a indicada por todos com quem se conversava sobre o processo histórico da colonização alemã em Teófilo Otoni.

Para análise de discurso empreendida no estudo dos relatos, considerou-se uma focalização teórica entre a Análise de Discurso Crítica e a Linguística Sistêmica Funcional proposta por Fairclough (2003), na qual o autor apresenta os significados acional, identificacional e representacional como uma recontextualização das funções ideacional, interpessoal e textual (Halliday,1991). Nesse sentido, considerase a análise discursiva como um nível intermediário de diálogo entre o texto e o seu contexto social.

Foram coletados dez relatos orais com descendentes de imigrantes alemães em Teófilo Otoni-MG, sendo esses os objetos de análise de discurso crítica

\footnotetext{
${ }^{4}$ Esta é a entrevistada 1, pessoa que desenvolve estudos sobre a imigração alemã na região e representa a comunidade de descendentes nos eventos nacionais.
}

R. Inter. Interdisc. INTERthesis, Florianópolis, v.12, n.2, p.74-94, Jul-Dez. 2015 
(FAIRCLOUGH, 1999; 2001; 2003). Para o levantamento dissertativo, escolheramse aleatoriamente aqueles que viveram, ainda que na infância, o período da segunda Grande Guerra (1939-1945). Assim, considerando esse critério de inclusão utilizado para formação do corpus, pode-se perceber que os relatores seriam pessoas mais idosas. No percurso da pesquisa, alguns informantes com quem foi feito o primeiro contato vieram a óbito (2) e outra, por perdas sofridas na família, recusou-se a continuar no trabalho. Tudo isso de certa forma limitou o grupo de informantes, o que também determinou que a abordagem contemplada seria o estudo de caso.

Assim, os resultados apresentados apontam para como os indivíduos desse grupo representam discursivamente suas práticas culturais, crenças e valores por meio da memória, um conjunto de escolhas eleitas para reivindicar a condição de descendência no território investigado.

\section{A CONJUNTURA DA IMIGRAÇÃO ALEMÃ}

A política imigratória no Brasil, voltada para o povoamento de terras devolutas (públicas) começa a ser implantada antes mesmo da independência do país, sendo os primeiros imigrantes assentados no regime de sesmarias na Bahia (1818) e no Rio de Janeiro (1819). Entretanto, tais colônias não foram bem sucedidas, tendo duração efêmera. Somente mais tarde, 1824, a fundação da colônia de São Leopoldo, no Rio Grande Sul - único empreendimento dessa natureza considerado bem sucedido, passa a ser um marco da imigração alemã no Brasil. A partir de então, de forma sistemática e estreitamente vinculada ao sistema de colonização, a imigração alemã se dá através da implementação da pequena propriedade agrícola familiar, tendo por objetivo o desenvolvimento da policultura com mão-de-obra familiar voltada para produção de alimentos, além da ocupação territorial (MALTZAHN, 2009, p. 01).

No Brasil, a localização das colônias alemãs aponta para os interesses mais diretos da política nacional de colonização com imigrantes, que era o povoamento de terras devolutas, consideradas mais adequadas à instalação de colonos estrangeiros livres e europeus (brancos). Nessas terras, os imigrantes ficavam 
isolados em zonas pioneiras não ocupadas pela grande propriedade (HUBER, 2008, p. 280) .

Em Minas Gerais, duas companhias dirigidas por particulares, associadas ao governo provincial, foram responsáveis pela introdução de imigrantes na Zona da Mata e no Vale do Mucuri: a Companhia União e Indústria, de Juiz de Fora, e a Companhia de Comércio e Navegação do Mucuri. Ambas foram responsáveis pela introdução de famílias de imigrantes, em sua maioria de origem germânica, para a construção de estradas nas regiões (FUNDAÇÃO JOÃO PINHEIRO, 1993, p. 23).

Com o objetivo de organizar o transporte fluvial e terrestre e localizar as glebas férteis da região, a Companhia de Comércio e Navegação do Mucuri foi fundada por Teófilo Benedito Otoni em 1851. (ROTHE,1956, p. 7).

O engenheiro Roberto Schlobach, e Otto Voigt, auxiliares diretos de Teófilo Benedito Otoni foram os primeiros alemães chegados, 1853. Nesse mesmo ano, a determinação de se estabelecer núcleos coloniais, confiados a imigrantes europeus, especialmente germânicos, fez com que Teófilo Benedito Otoni firmasse contrato com a Firma Schlobach e Morgenstern de Leipzig para vinda e dois mil agricultores alemães (ROTHE,1956, p.8).

Quanto ao procedimento utilizado para trazer imigrantes, tem-se que os agenciadores não hesitaram em oferecer vantagens não previstas nos programas de colonização (SEYFERTH, 2000, p.277). Há um discurso de sedução desses agenciadores quanto às benesses do território para onde viriam. Weyrauch (1997) faz referência também ao fato de alguns imigrantes acharem estar chegando à cidade americana de Filadélfia, conforme também relatado pela informante que declara ter havido algum tipo de 'enganação', nesse caso, pelos agenciadores.

Da família Nowmn eles não pensavam que estavam vindo para o Brasil, parece que houve uma tapeação...porque eles souberam que estavam indo para Filadélfia, e eles pensaram que estavam indo para Filadélfia dos Estados Unidos, ... local próspero... então colocaram o nome aqui Filadélfia, não sei se foi estratégia para atrair as pessoas [...] (RELATO ORALEntrevistada $1^{5}$ )

Os imigrantes trazidos por iniciativa da companhia foram instalados em duas áreas: a urbana, em que se concentravam vários tipos de especialistas, como

\footnotetext{
${ }^{5}$ Foi realizada uma pesquisa exploratória com uma descendente de alemães, em Teófilo Otoni. Entrevistada 1. R. Inter. Interdisc. INTERthesis, Florianópolis, v.12, n.2, p.74-94, Jul-Dez. 2015
} 
engenheiros, marceneiros, ferreiros, carpinteiros, oleiros, professores, enfermeiros, comerciantes e etc; e a área rural, onde se formaram as colônias agrícolas.

Além das dificuldades relativas ao desconhecimento da fauna e flora da região, do impacto das diferenças climáticas, a localização geográfica dos terrenos também representou dificuldades para os colonos.

Foram todos para os altos morros tanto que eles devem ter tido muita dificuldade para abrirem as estradas depois dos carreiros porque antes era só carreiro de burro... burro até que passa por aqueles morros, aquelas depressões... até hoje tem dificuldade por causa disso, quando eles querem comprar um trator [...] um micro trator... não tem como... é muito montanhoso o lugar onde foram colocados os alemães aqui [...] ( RELATO ORAL- Entrevistado 1)

Outro aspecto que aponta para a dificuldade encontrada pelos colonos diz respeito ao suprimento das necessidades básicas de alimento e vestuário, sobretudo nos primeiros anos após a chegada à colônia. "Os colonos tinham direito de fazer compras através de empréstimos no armazém da companhia e o pagamento era efetuado só após a primeira colheita. Tudo era anotado numa caderneta e o acerto se dava no final do mês[...]" ( FUNDAÇÃO JOÃO PINHEIRO,1993, p.60)

Achtschin (2009) afirma que além das dificuldades culturais, a relação de trabalho foi causa para muitas tensões entre os colonos e dirigentes locais.

No caso do vale do Mucuri, os gastos com a viagem, alimentação,
remédios, ferramentas e aquisição de lotes (a 300 mil réis) teriam que
ser pagos à Companhia em contratos de difícil entendimentos quanto
a valores, como questões cambiais, ou sistema de pesos e medidas
(palmas, arrobas, etc.). Com o preço do toucinho na região a mil e
trezentos réis e a farinha a 400 réis, a oferta de trabalho a 640
réis/dia seria compatível ao árduo trabalho das obras da estrada
Santa Clara? Para piorar, os preços dos produtos elevavam
constantemente, sendo que o feijão, em 1860 , chegou a quatro mil
réis e o arroz a três mil réis. Para se ter uma ideia da diferença
salarial, o engenheiro polaco Christiano Wyzeuski recebia cinco mil
réis por dia [...](ACHTSCHIN,2009, p.30)

O relato de uma descendente ainda aponta uma outra perspectiva sobre as relações de trabalho:

[...] as terras não foram doadas não... os colonos compravam as terras... tanto que o Theófilo Benedito ${ }^{6}$, pelo que a história nos conta pediu que fossem selecionadas as pessoas que tivessem um capital para comprar essa terra... tanto que todos eles compraram e pagaram...agora 0 pagamento dessas terras era feito com produtos da terra porque circular dinheiro aqui... o que a gente sabe que não circulava...eles parece que tinham um certo medo de que os alemães e já os filhos voltassem para

${ }^{6}$ Theófilo Benedito Otoni foi o fundador da cidade de Teófilo Otoni-MG e também o político que dirigiu a companhia de Comércio e Navegação do Mucuri.

R. Inter. Interdisc. INTERthesis, Florianópolis, v.12, n.2, p.74-94, Jul-Dez. 2015 
Alemanha ou fossem para outros locais... então eles não deixavam circular dinheiro aqui não [...] ( RELATO ORAL- Entrevistado 1)

Nos relatos históricos e também na literatura pode-se perceber a descrição desse processo permeado pelos conflitos de terra e pelos relatos sobre o cansaço para derrubar a mata e cultivar os lotes sem a utilização dos métodos tradicionais europeus. Problemas como o povoamento disperso, precariedade de estradas e transporte, problemas de abastecimento de alimentos e vestimentas, doenças, o endividamento e a dependência em relação aos comerciantes estabelecidos marcam esse período de ocupação territorial, e na literatura, contribuem para a construção da figura do "pioneiro", desbravador de florestas e fundador de colônias alemãs (HUBER, 2010, p. 73).

Assim exposto, pode-se perceber que a imigração alemã no Brasil e no Vale do Mucuri apresenta traços característicos semelhantes, marcados simbolicamente pelo pioneirismo, isolamento e o campesinato característico das regiões de colonização, cujo fundamento está na propriedade familiar.

A seguir serão abordados os conceitos relativos aos aspectos desterritorializadores e re- territorializadores no processo de formação da cidade de Teófilo Otoni- Minas Gerais. Cabe ressaltar que o objeto de estudo foi o relato, e portanto, a linguagem, mas as práticas de linguagem são formas de territorialidades simbólicas na medida em que compreendem relações que apresentam regras compartilhadas, portanto, fomentadas pelas relações sociais e de poder estabelecidas no território, o que justifica esta abordagem.

\section{A DESTERRITORIALIZAÇÃO DO IMIGRANTE E A CONSTRUÇÃO DE TERRITORIALIDADES}

Considerando a questão da migração como aspecto importante da Geografia Cultural, Sayad afirma que a imigração em si é um produto de relações de forças. Nas palavras do autor "o país receptor assume sempre uma relação de poder dominante com relação ao imigrante", até porque é ele que oferece em seu território possibilidades de emprego e de melhoria de vida ou de consumo (SAYAD, 2000, p.17). 
É sob essa perspectiva que muitos acreditam que a imigração se apresenta como um processo desterritorializador, o que é contestado por Haesbaert (2005), que critica os discursos correntes que afirmam que grande parte da humanidade vive processos violentos de desterritorialização. Para o geógrafo,

o mito da desterritorialização é o mito dos que imaginam que o homem pode viver sem território, que a sociedade pode existir sem territorialidade, como se o movimento de destruição de territórios não fosse sempre, de algum modo, sua reconstrução em novas bases (HAESBAERT, 2007, p.16)

Haesbaert define o termo "territorializar-se" como a possibilidade de criação de referenciais simbólicos num dado espaço em movimento. Para o autor, a territorialização ocorre por meio das relações de domínio e apropriação do espaço, ou seja, das mediações espaciais do poder, poder em sentido amplo, que se estende do mais concreto ao mais simbólico.

No caso em estudo, os alemães que vieram para Teófilo Otoni já viviam uma situação em que o acesso e ou delimitação da terra, enquanto forma de sobrevivência, já era insolvente e esse território, na sua dimensão física, dominado espacialmente, como também eram os homens e as relações sociais que ali se estabeleciam. Assim sendo, esses imigrantes eram dominados e/ou controlados politicamente tanto da sua partida- saída da Alemanha, como na sua chegada ao Brasil.

Em meio às dificuldades decorrentes da paisagem desconhecida, estabeleceram relações sociais e, mesmo tendo perdido importantes elementos da vida cotidiana, buscaram reproduzir as referencialidades de espaço (territorial e/ou cultural), perdidas com a migração.

Diante do exposto pode-se perceber que a desterritorialização e a reterritorialização são processos indissociáveis ( Haesbaert, 2007). Se a imigração para o Brasil representou um processo de desterritorialização, a chegada à região foi desafiadora e exigiu desses imigrantes uma reprodução de elementos do território anterior - reterritorialização - através do desenvolvimento de técnicas para lidarem com o solo e a topografia, a produção dos lugares, a religião, de outro modo, a dominação e apropriação do espaço natural.

Ao mesmo tempo, a territorialidade pode ser identificada/perceptível no discurso como consequência dessas relações econômicas, políticas e culturais. Ou seja, a história da imigração alemã em Teófilo Otoni, representada em relatos dos R. Inter. Interdisc. INTERthesis, Florianópolis, v.12, n.2, p.74-94, Jul-Dez. 2015 
descendentes por meio de seus discursos, manifestam diversos aspectos que contribuem para a compreensão, dentre outros elementos, das territorialidades existentes, bem como para a identificação de traços identitários do grupo de descendentes (re) territorializados.

\section{A ANÁLISE DISCURSIVO- CRÍTICA DE RELATO}

Reconhecendo o discurso como um aspecto importante na vida social, o presente estudo destaca a Análise de Discurso Crítica como referencial teórico metodológico por este contemplar não só a análise linguística, mas também a crítica social e o momento sócio histórico em que o discurso está inserido. Dessa forma pode ser compreendida como uma forma de análise que articula a análise textual a contextos sociais amplos, com o propósito de mostrar " como a língua participa de processos sociais"(FAIRCLOUGH, 2001, p.229).

Para Fairclough (2012) a ADC é a análise das relações dialéticas entre semioses ( inclusive a língua) e outros elementos das práticas sociais, sendo três as maneiras de atuação da semiose. A primeira, atua como parte de uma atividade social inserida numa prática, assim consideram-se os gêneros, que são definidos pelas práticas sociais a eles relacionados. Fairclough (2003 a) defende que cada prática social produz e utiliza gêneros discursivos, que por sua vez articulam estilos e discursos relativamente estáveis em contextos sócio históricos e culturais. Dessa forma os discursos constituem parte dos recursos com que as pessoas se posicionam no relacionamento, umas com as outras - mantendo-se separadas, cooperando, competindo, dominando.

A semiose atua também nas representações, ou seja, para proceder a Análise de Discurso Crítica faz-se necessário considerar as diferentes representações de mundo que se presentificam nos discursos, de outro modo, é possível identificar no discurso as diferentes relações que as pessoas estabelecem com o mundo e que dependem das suas posições e das relações que estabelecem com outras pessoas ( FAIRCLOUGH, 2012).

Além disso, os atores sociais produzem representações de modo distinto, variando portanto, de acordo com o lugar que ocupam dentro de suas práticas. Cada 
posição é, portanto, desempenhada com estilos diferentes, sendo assim, maneiras de ser, identidades, em seu aspectos semiótico.

O estudo contemplou o enquadre de ADC proposto por Chouliaraki e Fairclough (1999), no qual toda análise parte da percepção de um problema, que, segundo Resende e Ramalho (2009, p. 36) "baseia-se em relações de poder, na distribuição assimétrica de recursos materiais e simbólicos em práticas sociais, na naturalização de discursos particulares como sendo universais".

Como segundo passo para a análise, a identificação de obstáculos se torna a compreensão das implicações desse processo, ou seja, a identificação de elementos da prática social que sustentam a questão sociocultural, ou contribuem para estabelecê-lo enquanto um problema social. Nesse sentido, faz-se necessário considerar não apenas obstáculos em práticas sociais locais, mas também globais, por isso foi apresentado o contexto da imigração alemã no Brasil, em Minas Gerais e no Vale do Mucuri, representando, portanto, a análise da conjuntura.

Há um perfil comum no contexto da imigração alemã no Brasil, que é o assentamento em áreas de florestas e a demarcação de lotes acompanhando os vales dos rios, como também é comum o fato que o desenvolvimento dos projetos de colonização se caracterizou pela desorganização, quase sempre provocada pela falta de recursos públicos para os assentamentos. (SEYFERT, 201177).

Tais fatores representam a causa para as dificuldades extremas encontradas pelos 'pioneiros', no entanto, foram também responsáveis para uma forte organização comunitária, em torno da pequena propriedade agrícola familiar, ou mesmo nas áreas urbanas.

Outro aspecto significativo que pode ser apontado na análise da conjuntura é a forma como os imigrantes vieram, já que tanto os registros bibliográficos quanto o relato oral de descendente coletado para este trabalho versam sobre 'oferta de falsas vantagens' ou 'tapeação', o que sugere decepção, descontentamento na chegada desses colonos. Além disso, têm-se registros de dívidas dos imigrantes, uma vez que as compras eram feitas no armazém da Companhia e debitadas em cadernetas e o pagamento era feito com a produção agrícola, portanto, 'dinheiro

7 Identidade étnica, assimilação e cidadania: A imigração alemã e o Estado brasileiro. Disponível em: http://www.anpocs.org.br/portal/publicacoes/rbcs2608htm Acesso em 30 de agosto de 2011. 
não circulava por aqui' (Relato Oral - Entrevistada 1), o que para eles representava a impossibilidade de se buscar outras alternativas. Dessa forma, eram impedidos de migrar para outras regiões ou mesmo para o país de origem.

Por fim, a análise discursiva contempla o relato de uma descendente de imigrantes alemães em Teófilo Otoni em um contexto do vivido na infância ou do representado pelos parentes próximos. Por isso, sua representação é atravessada por dizeres que representam os dizeres locais sobre a experiência da chegada e adaptação, onde se pode perceber as relações entre os nativos e os imigrantes, como também, entre os próprios imigrantes da mesma etnia, já que conforme exposto anteriormente, esses eram divididos de acordo com interesses dos empreendedores locais, e não por opção ou aptidão.

Considerando a correspondência proposta por Fairclough(2003a) entre ação e gênero, representação e discurso e identificação e estilo, a análise aqui apresentada, concernente ao significado acional, traz o gênero relato de uma descendente de alemães de quarta geração. Isso foi representado no texto pelo distanciamento ou aproximação da narradora do fato narrado, já que quando conta como os alemães ficaram sabendo da possibilidade de vir para o Brasil, como foi a decisão de migrar ela utiliza a terceira pessoa do plural. "[...] eles não pensavam que estavam indo para o Brasil... eles souberam que estavam indo para Filadélfia dos Estados Unidos..." . Ao mesmo tempo, há passagens em que se aproxima do evento narrado "[...] meu pai ainda lembra que ele lidava com ferro...", ou mesmo, em avaliações ou presunções valorativas, a narradora se mostra, [...] não sei se foi estratégia para atrair as pessoas... "[...] e eu atribuo esse progresso ao conhecimento trazido da Europa...".

Chouliaraki e Fairclough (1999) afirmam que um gênero é um mecanismo articulatório que controla o que pode ser dito e como pode ser dito, afirmando então que esses precisam ser compreendidos como a faceta regulatória do discurso. A utilização da terceira pessoa do plural no relato em análise apresenta-se um "discurso multifacetado", ora sugere a voz dos imigrantes pioneiros, ora uma indeterminação dos agentes responsáveis pela ação, uma impessoalização "[...] eles lá na Alemanha ouviram falar ..." "[...] colocaram o nome aqui Filadélfia, não 
sei se foi estratégia para atrair pessoas...", "[...] eles parece que tinham um certo medo de que os alemães e já os filhos voltassem para Alemanha...".

Percebe-se, por vezes, que o texto relatado estabelece intertextualidade com os registros em livros de historiadores, bem como com o relato de descendentes. Podem-se perceber vozes excluídas, como por exemplo, a do camponês, o descendente que ainda hoje reside em áreas rurais e vive da terra, como também a relação harmônica entre a voz do descendente alemão e a dos historiadores. Entretanto, a relação de conflito fica também evidenciada:

[...] as terras não foram doadas não... os colonos compravam as terras... tanto que o Theófilo Benedito, pelo que a história nos conta pediu que fossem selecionadas as pessoas que tivessem um capital para comprar essa terra... tanto que todos eles compraram e pagaram...agora 0 pagamento dessas terras era feito com produtos da terra porque circular dinheiro aqui... o que a gente sabe que não circulava...eles parece que tinham um certo medo de que os alemães e já os filhos voltassem para Alemanhã ou fossem para outros locais... então eles não deixavam circular dinheiro aqui não [...] ( RELATO ORAL- Entrevistada 1) ${ }^{8}$

O fragmento acima também ilustra a interdiscursividade, de outra forma, a representação de diferentes atores sociais, significado representacional. Rezende e Ramalho (2009, p.72) afirmam que "as maneiras como os atores sociais são representados no texto podem indicar posicionamentos ideológicos em relação a eles e a suas atividades". Pode-se notar que diferentes discursos são articulados: o discurso dos colonos, imigrantes pioneiros; o da história; o de Teófilo Benedito Otoni; e outro sem nome, que sugere as pessoas que compunham o grupo dominante, que detinham o poder na região, mas do qual Teófilo Benedito Otoni não fazia parte.

Van Leeuwen (1997,p.200) apud Rezende e Ramalho(2009, p. 73) explica que:

As personagens sem nome cabem apenas papéis passageiros e funcionais, elas não se tornam pontos de identificação para o leitor [...] a representação por nomeação (em que nomes próprios são citados), de certa forma, significa uma valorização do autor nomeado.

Assim, o discurso sem nome, 'sem pontos de identificação para o leitor' é de certa forma negligenciado, ao passo que o discurso de dominação, autoridade, é conferido e legitimado enquanto poder ao fundador da cidade, Teófilo Benedito Otoni. Rajagopalan (2003, p.82) apud Rezende e Ramalho (2009, p. 76) sustenta

${ }^{8}$ Grifo das autoras

R. Inter. Interdisc. INTERthesis, Florianópolis, v.12, n.2, p.74-94, Jul-Dez. 2015 
que " o processo de nomeação é um ato eminentemente político, uma vez que a influência da mídia na opinião pública, favorável ou contrária a personalidades e acontecimentos noticiados, começa no ato da designação".

O discurso da relatora que assume o papel social de descendente de quarta geração de imigrantes alemães, ora se apresenta enquanto um discurso de cooperação, e portanto resolução dos problemas da vida, bem como concordância com o discurso dominante, ora se apresenta como um discurso de competição, segundo o qual um deles assume o papel de protagonista e outro de antagonista, e assim sendo, a articulação entre eles serve para negar um discurso em detrimento do outro ( RESENDE E RAMALHO, 2009).

No significado identificacional, "estilos constituem o aspecto discursivo de identidades, ou seja, relacionam-se à identificação de atores sociais em textos" ( RESENDE E RAMALHO, 2009, p.76). Assim, nesse recorte encontraram-se traços identitários relativos aos valores, bem como ao modo de representação da cidadania estrangeira.

Todos eram chamados de alemães... os belgas, holandeses tudo era alemão... mas isso aí o elo foi a língua...a dificuldade de comunicação então eles começaram a se comunicar porque eles todos sabiam mais ou menos e era uma língua mais parecida e como a maior número eram alemães então a língua era o elo de ligação e depois o principal talvez foi o pastor Hollerbach. (RELATO ORAL- Entrevistada 1).

Na passagem acima, tem-se a proposição como função discursiva, quando a relatora marca o grau de probabilidade de ser a religião e a língua responsáveis pela germanização na região. A princípio, pode-se perceber que o emprego do advérbio modal "talvez" aponta para a possibilidade de ser, entretanto, no final ela reafirma categoricamente que a presença do pastor foi responsável pela germanização na região. A utilização desse verbo sinaliza o valor da religião, bem como para o discurso de dominação, aqui no caso específico, o discurso religioso, o que pode ser caracterizado em outra passagem.

[ ...] o que é mais marcante... da cultura alemã aqui é a religião. Porque aí nós temos duas igrejas evangélicas luteranas, uma religião trazida da Alemanha da reforma de Martin Lutero [...] ( relato oral- Entrevistada 1).

Religião, educação é um aspecto muito forte porque o Lutero ele brigava com os governadores da época dele para que instituíssem escolas públicas para o povo porque o povo precisava estudar para interpretar a bíblia de forma correta, então esse modelo de escola pública que temos foi um modelo instituído por Lutero na Alemanha [...] (RELATO ORALEntrevistada 1).

R. Inter. Interdisc. INTERthesis, Florianópolis, v.12, n.2, p.74-94, Jul-Dez. 2015 
Segundo Maltzahn (2009), a noção de germanidade afirma uma dupla identidade. De um lado o pertencimento à nação alemã, compreendida como entidade étnica, cultural e linguística, por outro, o pertencimento à pátria e ao Estado brasileiro, compreendido como entidade territorial e política. A construção identitária aqui representada no discurso de relato é a legitimadora (Castells, 1999), uma vez que o discurso religioso parece assumir autoridade e elevado valor para os descendentes de alemães em Teófilo Otoni. Além da religião, outro aspecto apontado como valor é a educação, e a esta é conferido um estatuto de superioridade à educação atual, sobretudo devido ao seu cunho religioso, o que pode ser comprovado na passagem do relato que apresenta afirmação avaliativa e presunções valorativas.

Outra coisa que é também muito relevante para os descendentes de alemães é a educação, tanto que o pastor Holleback foi talvez o educador que mais tempo trabalhou aqui, assim educando pessoas não só da descendência alemã, mas todos que se aproximavam dele, tanto que o avô do nosso ex governador Aércio Neves estudou na escola do Pastor Holleback, já não era o Pastor Hollebarch mais mas tinha aquele princípio aquele fio de educação alemã deixado pelo pastor Hollebarch [...] ( RELATO ORAL- Entrevistada 1) ${ }^{9}$

Seyfert ${ }^{10}$ afirma que a elaboração de uma forte organização comunitária serviu de respaldo ideológico a um dos temas preferidos do discurso étnico: o "trabalho alemão", o que fica claro na passagem do relato destacada: "Olha eles vieram com tanta vontade de trabalhar, de plantar e de colher que eu acredito que eles se adaptaram logo a essas dificuldades (...)" A mesma autora acrescenta que a etnicidade teuto-brasileira é resultado das especificidades apresentadas nas organizações presentes nas colônias e que o discurso étnico se serviu de um modelo que ratifica a ideia de pioneirismo para dar destaque à colonização como produto desse "trabalho alemão", numa clara suposição de superioridade racial, perceptível pelo trecho "eu atribuo esse progresso ao conhecimento trazido da Europa":

\footnotetext{
${ }^{9}$ Grifos da autora.

${ }^{10}$ Identidade étnica, assimilação e cidadania: A imigração alemã e o Estado brasileiro. Disponível em: http://www.anpocs.org.br/portal/publicacoes/rbcs2608htm Acesso em 30 de agosto de 2011.
} 
[...] então a gente sabe que eles progrediram muito aqui, produziram muito, tanto que por essa produção enorme que se efetivou aqui veio depois a estrada de ferro Bahia e minas que foi inaugurada em 1882... 1888... então isso é que foi a amostra maior do progresso do Mucuri com o trabalho e com o desenvolvimento e eu atribuo esse progresso ao conhecimento trazido da Europa por aqueles europeus...alemães, belgas, franceses... todos vieram com uma certa profissão...aprendida lá, desenvolvida lá, que levou lá ao progresso e que certamente trouxe o progresso para cá também [...]( RELATO ORAL- Entrevistada 1).

Pode-se perceber no fragmento na passagem do relato o estabelecimento de um embate discursivo entre as identidades legitimadora e de resistência. A primeira, aqui tomada como a verdade do discurso dos historiadores e do próprio fundador da cidade, Teófilo Benedito Otoni, e a de resistência, representada pelo discurso dos descendentes de imigrantes alemães, uma vez que esses negam o discurso do senso comum de que os alemães que para cá vieram eram menos qualificados. Vale lembrar que a condição da descendência é ressaltada como identidade oriunda de nacionalidade "superior" ou pertença étnica à condição de ser de "origem europeia".

Há também uma passagem em que a relatora fala da sua representação étnica como sendo brasileira, "Eu sou brasileira, NÉ? Eu vejo o alemão assim meio radical, muito sério, muito compromissado, o brasileiro é mais alegre vamos dizer assim, mais menos radicais, então eu acho que da mistura desses dois povos seriedade e alegria dá uma mistura muito boa..." A utilização do marcador conversacional "né" busca a adesão e possível confirmação na interlocução, ou seja, ao mesmo tempo em que afirma, sugere dúvidas a ponto de se buscar a confirmação na interação. A forma como representa o alemão é marcada por adjetivos e advérbios, em atributos e circunstâncias que conferem uma avaliação positiva das duas etnias, porém, percebe-se uma presunção valorativa, de outro modo, o que está sendo dito se baseia em presunções não ditas, como por exemplo a rigidez, radicalidade, compromisso e seriedade do alemão sugerem uma superioridade ética e étnica.

Por fim, uma análise crítica, conforme o próprio Fairclough (2012) sugere, carrega os aspectos linguísticos, bem como o contexto, as questões sociais, refletindo sobre as interrelações entre as teorias sociais e as discursivas como cruciais para compreender uma determinada questão. Nesse sentido, compreender o relato de uma descendente, significa compreender os posicionamentos assumidos 
a partir das identidades e das práticas representadas. Desse modo, a descendente se coloca como agente social que representa o próprio grupo dotado de aspectos da germanização, mas também com práticas brasileiras e dos migrantes, representando nesse processo os problemas advindos da chegada e a superação desses a partir do próprio olhar.

\section{CONSIDERAÇÕES FINAIS:}

A linguagem é interação, marca de expressão, experiências e ideias, mas é sobretudo, uma prática que constitui o social, os objetos e os sujeitos sociais, ao mesmo tempo em que é constituída por eles. Nesse sentido, materializa discursos que podem servir para instauração, sustentação ou transformação de relações assimétricas de poder. Analisar os discursos enquanto momento de práticas sociais ou mesmo constitutivos dessas implica o trabalho meticuloso de articulá-los a contextos complexos e por vezes obscuros, sendo papel do analista em ADC identificar tais relações, bem como o modo como se articulam para que sentidos possam ser construídos.

Portanto, é indiscutível a relevância da ADC enquanto instrumental teórico metodológico para análise de discursos velados, cristalizados, reproduzidos, legitimados, inquestionados.

A chegada dos imigrantes alemães em Teófilo Otoni/MG aparece sempre associada ao processo de formação da cidade ou à Companhia de Comércio e Navegação do Rio Mucuri. Normalmente, as publicações, inclusive as acadêmicas, trazem a inexpressividade dos empreendimentos coloniais na região, justificando que apenas um pequeno contingente permaneceu, apesar dos problemas econômicos (Falência da Companhia de Comércio e Navegação do Rio Mucuri). Entretanto, sugerem-se mais estudos acerca das representações trazidas pelos grupos de descendentes, até porque a representação é um modo de ser/fazer/ dizer através do qual se estabelecem identidades individuais e coletivas.

Pela análise discursiva apresentada pôde-se observar que a religião, a educação e a língua são referenciados como valores positivos, além do trabalho pioneiro dos 'desbravadores'. Assim, pôde-se perceber o quanto a utilização da 
Análise de Discurso Crítica constituiu-se importante recurso para a pesquisa, até porque apontou que o trabalho com os relatos mostra que a lembrança ou mesmo a escolha dos dizeres sobre o passado pode estar assim vinculada àqueles que têm o poder, que decidem o que deve ser lembrado ou esquecido, o que para Pollak (1989:p.3-15) seria "a luta entre a memória oficial e as memórias subterrâneas", esse embate que se trava entre memórias silenciadas, marginalizadas e a memória oficial representa, sobretudo, uma afirmação de uma identidade, que se instaura, pelo relato da descendente entrevistada, assumindo representações da descendência europeia da "organização" e "conhecedora das coisas".

O presente artigo não se encerra aqui, uma vez que se identificou, por meio da Análise do Discurso Crítica do relato de uma descendente, que podem existir outras leituras, outras abordagens históricas e diferentes representações identitárias da imigração alemã em Teófilo Otoni. Assim, este é apenas o começo de uma pesquisa! 


\title{
DISCOURSES AND TERRITORIALITIES IN THE ACCOUNTS OF GERMAN IMMIGRANTS DESCENDANTS IN TEOFILO OTONI - MG
}

\begin{abstract}
:
This essay has the objective to discursively analyze the report of German immigrants descendants in Teófilo Otoni, by highlighting the methodological theoretical framework from Chouliaraki and Fairclough (1999), as well as Fairclough's reflections that emphasizes conjectures of how the speech fits into social life. To analyze the reports from the mentioned framework also calls for the remission to all sociohistorical context in which the language as social practice also implies in a social moment that others represent themselves and their actions by bringing re-meanings. Thus, we present the German immigration in Brazil, in the Vale do Mucuri, especially in Teófilo Otoni-MG. Then, we discuss the social relationships that involve the dispossession of the immigrant territory and the construction of new territoriality. Finally, we present a critical discourse analysis, heading both the meanings proposed by Fairclough (2003). In the ational meaning, we focused on the gender report and on the inter-textual category, that allowed the identification of the voices articulated in the speech. In the representational meaning, we focused on the interspeech category when we could see cooperation and/or competition speeches. In the identificational meaning, we highlighted the category as well as the evaluation, from when we could see representations of legitimized identities and resistance. Also, we identified traits that gift the language values held by the German immigrants descendants, when related to work and above all, to religion.

Keywords: Language. Speech. Immigration. Deterritorialization. Territoriality

\section{UNA VISIÓN CRÍTICA DISCURSIVA DEL RELATOS DE LOS DESCENDIENTES DE INMIGRANTES ALEMANES EN TEÓFILO OTONI - MG: CONSTRUYENDO NUEVAS TERRITORIALIDADES}

\section{Resumen:}

Este artículo presenta los resultados de un estudio que tuvo como objetivo analizar, desde el punto de vista discursivo y crítico el relato de los descendientes de inmigrantes alemanes en Teófilo Otoni, priorizando teórica y metodológicamente el punto de vista de Chouliaraki y Fairclough (1999) y Fairclough (2003), cuyas conjeturas enfatizan cómo el discurso es parte de la vida social. Analizar el relato desde ese enfoque demanda la remisión a todo el contexto socio-histórico, ya que el lenguaje como práctica social implica un momento social en el que otros se representan y representan sus acciones trayendo (re)significados. Así, presentamos la inmigración alemana en Brasil, en el Valle del Mucuri y especialmente en Teófilo Otoni, MG. A continuación, una discusión sobre las relaciones sociales que implican la desterritorialización de los descendientes de los inmigrantes y la construcción de nuevas territorialidades. Por último, se presenta el análisis crítico del discurso, utilizando los significados propuestos por Fairclough (2003). En el significado accional, se centró en el género relato y la categoría de intertextualidad, cuando se identificó las voces articuladas en el discurso. En el significado representacional, proponemos la categoría de interdiscursividad, cuando se puede percibir los discursos de cooperación y/o competencia. En el significado identificacional, se destacó la modalidad, así como de la evaluación, cuando se pudo percibir las 
representaciones de las identidades legitimadoras y de resistencia. Además, se identificaron rasgos que le confieren a la lengua, al trabajo $y$, sobre todo, a la religión, los valores mantenidos por los descendientes de inmigrantes Alemanes.

Palabras clave: Lenguaje. Discurso. Inmigración. Desterritorialización. Territorialidad. 


\section{REFERÊNCIAS}

ACHTSCHIN, M. Os "Desclassificados" do Mucuri: Tensões e Conflitos em Santa Clara e Colônia do Urucu no século XIX. In: ACHTSCHIN, M.(org.)As Gerais Distantes das Minas: Fragmentos da História do Vale do Mucuri.Teófilo Otoni: Frota,2009.78p.

CHOULIARAKI, L. \& FAIRCLOUGH, N. Discourse in late modernity: rethinking Critical Discourse Analysis. Edinburg: Edinburg University Press, 1999.

FAIRCLOUGH, N. Discurso, mudança e hegemonia. In: Pedro. E.R (org.). Análise crítica do discurso: uma perspectiva sociopolítica e funcional. Lisboa: Caminho, 1997, PP. 77-104.

FAIRCLOUGH, N.Discurso e mudança social. Brasília: Editora UnB, 2001a.

FAIRCLOUGH, Norman. Analysing Discourse: textual analysis for social research. London: Routledge, 2003.

FAIRCLOUGH, Norman. Language and Glogalization. London: Routledge, 2006. FAIRCLOUGH, 2003.

FAIRCLOUGH, N. Análise Crítica do Discurso como método em pesquisa social científica. Linha D’Água, n. 25 (2), p. 307-329, 2012.

FUNDAÇÃO JOÃO PINHEIRO. Centro de Estudos Históricos e Culturais. A colonização alemã no Vale do Mucuri. Belo Horizonte, 1993, 162p.

HAESBAERT, Rogério. O mito da desterritorialização: do "fim dos territórios" à multiterritorialidade. $3^{\mathrm{a}}$ ed. Rio de Janeiro, Bertrand Brasil. 2007.

HUBER, Valburga. A literatura da imigração alemã e a imagem do Brasil. In: PACELLI, Ademir et al (Orgs.) A experiência migrante: entre deslocamentos e reconstruções. Rio de Janeiro: Garamond, 2010. p. 69 - 96.

GAZZINELLI, Cibele M. Diniz Figueirêdo. Discursos sobre a imigração: relatos de descendentes alemães na cidade de Teófilo Otoni. 2014. 98 f. (Mestrado em 
Gestão Integrada de Território)- Universidade Vale do Rio Doce - UNIVALE, Governador Valadares, 2014.

MALTZAHN, Paulo César. Construção e formação de identidade étnica teutobrasileira: algumas considerações. In: Congresso Internacional de História, 2009, Maringá. Anais do IV Congresso Internacional de História, 2009. Disponível em: http://www. pph.uem.br/cih/anais/trabalhos/180.pdf Acesso em: 30 de ago. de 2011.

ROTHE, M. ET.al. 100 anos de imigração alemã em Teófilo Otoni. ljuí, Correio Serrano,1956.

REZENDE, Viviane de Melo; RAMALHO, Viviane. Análise de discurso crítica. São Paulo: contexto, 2009.

SAYAD,Abdelmalek. O retorno segundo Abdelmalek Sayad. Travessia, São Paulo, v. Especial, p.3 -33, jan.2000.

SEYFERT, Giralda. "As identidades dos imigrantes e o melting pot nacional”. In Horizontes Antropológicos. Porto Alegre: Programa de Pós-Graduação em Antropologia Social, UFRGS. IFCH. Ano 6, n.14,2000. Disponível em:

http://www.scielo.br/pdf/ha/v6n14/v6n14a07.pdf Acesso em: 18 de jul. 2011.

SEYFERT, Giralda., Identidade étnica, assimilação e cidadania: A imigração alemã e o Estado brasileiro. Disponível em:

http://www.anpocs.org.br/portal/publicacoes/rbcs 00 26/rbcs26 08.htm Acesso em: 24 de out. de 2011.

WALLACE, M. The case study approach. In: WALLACE, M. Action Research for Language Teachers. Cambridge: Cambridge University Press. 1998. p.160-180.

WEYRAUCH, Cléia Schiavo. Pioneiros Alemães de Nova Filadélfia. $1^{\text {a }}$ Ed. Caxias do Sul:EDUCS, 1997.

Artigo

Recebido em 03 de março de 2015

Aceito em 12 de outubro de 2015 